\title{
Solvability for an impulsive fractional multi-point boundary value problem at resonance
}

\section{Yi Chen ${ }^{1 *}$, Zhanmei Lv² and Zhenhua Xu ${ }^{3}$}

\section{"Correspondence:} mathcyt@163.com

${ }^{1}$ Department of Mathematics, China University of Mining and

Technology, Xuzhou, 221116 P.R. China

Full list of author information is available at the end of the article

\begin{abstract}
In this paper, we consider the fractional multi-point boundary value problem with impulse effects. As indicated by M Fečkan, Y Zhou and JR Wang in 2012, the concepts of piecewise continuous solutions used in most of the current literature about the impulsive differential equations of fractional order are not appropriate. Based on a new concept of a piecewise continuous solution, we establish sufficient conditions for the existence of the solutions for the boundary value problem at resonance by the continuation theorem of coincidence degree theory.
\end{abstract}

MSC: 26A33; 34A08; 34A37

Keywords: fractional differential equations; impulsive differential equations; coincidence degree; at resonance

\section{Introduction}

In this paper, we are concerned with the existence of the impulsive differential equation of fractional order

$$
\left\{\begin{array}{l}
{ }^{C} D_{0+}^{\alpha} u(t)=f\left(t, u(t), u^{\prime}(t)\right), \quad t \in J^{\prime}, \\
\Delta u\left(t_{k}\right)=I_{k}\left(u\left(t_{k}^{-}\right), u^{\prime}\left(t_{k}^{-}\right)\right), \quad k=1,2, \ldots, p, \\
\Delta u^{\prime}\left(t_{k}\right)=J_{k}\left(u\left(t_{k}^{-}\right), u^{\prime}\left(t_{k}^{-}\right)\right), \quad k=1,2, \ldots, p, \\
u(0)=0, \quad u^{\prime}(1)=\sum_{j=1}^{m-2} \sigma_{j} u^{\prime}\left(\xi_{j}\right),
\end{array}\right.
$$

where ${ }^{C} D_{0+}^{\alpha}$ is the Caputo fractional derivative, $1<\alpha \leq 2, f:[0,1] \times \mathbb{R} \times \mathbb{R} \rightarrow \mathbb{R}$ is continuous, $I_{k}, J_{k}: \mathbb{R} \times \mathbb{R} \rightarrow \mathbb{R}(k=1,2, \ldots, p)$ are continuous, $0=t_{0}<t_{1}<t_{2}<\cdots<t_{p}<t_{p+1}=1$, $J=[0,1], J^{\prime}=J \backslash\left\{t_{1}, t_{2}, \ldots, t_{p}\right\}, \sigma_{j} \in \mathbb{R}, \xi_{j} \in(0,1), j=1,2, \ldots, m-2, m, p \in \mathbb{N}, m>2, p>0$, and $\Delta u\left(t_{k}\right)=u\left(t_{k}^{+}\right)-u\left(t_{k}^{-}\right)$, where $u\left(t_{k}^{+}\right)$and $u\left(t_{k}^{-}\right)$denote the right and left limit of $u(t)$ at $t=t_{k}$ $(k=1,2, \ldots, p)$, respectively. $\Delta u^{\prime}\left(t_{k}\right)$ has a similar meaning for $u^{\prime}(t)$. Further, we assume that

$$
\xi_{i} \neq t_{k}, \quad k=1,2, \ldots, p, i=1,2, \ldots, m-2
$$

and

$$
\sum_{j=1}^{m-2} \sigma_{j}=1,
$$

\section{并 Springer}

(0) 2014 Chen et al.; licensee Springer. This is an Open Access article distributed under the terms of the Creative Commons Attribution License (http://creativecommons.org/licenses/by/4.0), which permits unrestricted use, distribution, and reproduction in any medium, provided the original work is properly credited. 
which implies that the problem (1.1) is at resonance. The problem (1.1) happens to be at resonance in the sense that the kernel of the linear operator ${ }^{C} D_{0+}^{\alpha}$ is not less than onedimensional under the boundary value conditions.

Fractional calculus is a generalization of the ordinary differentiation and integration. It has played a significant role in science, engineering, economy, and other fields. Some books on fractional calculus and fractional differential equations have appeared recently (see [1-3]), and there are a large number of papers dealing with the fractional differential equations (see [4-17]) due to their various applications.

Impulsive differential equations have found its importance in realistic mathematical modeling of the phenomena in both the physical and the social sciences. The boundary value problem of impulsive differential equation has been investigated extensively in the literature; see $[9,10,12,15,18,19]$ and references therein.

There are some papers considering the fractional impulsive differential equations today. However, in $[9,15]$, the authors indicated that the concept of piecewise continuous solutions used in most of the current literature about the impulsive differential equations of fractional order are not appropriate.

Motivated by the papers $[6,8,9,11,15,17,20]$, in this paper we deal with the problem (1.1). Based on the new concept of a piecewise continuous solution presented in $[9,15]$, we establish some existence results about the problem (1.1). As far as we know, there are few papers to deal with fractional differential equations with impulses under resonant conditions.

The rest of the paper is organized as follows. In Section 2, we introduce some notations, definitions, and preliminary facts that will be used in the remainder of the paper. In Section 3, applying the results listed in Section 2, we prove the existence of the solution for the problem (1.1) by the coincidence degree theory. Then an example is given in Section 4 to demonstrate the application of our results.

\section{Preliminaries}

First of all, we present the necessary definitions and fundamental facts on the fractional calculus theory. These can be found in $[1,3]$.

Definition 2.1 $([1,3])$ The Riemann-Liouville fractional integral of order $v>0$ of a function $h:[0,1] \rightarrow \mathbb{R}$ is given by

$$
I_{0+}^{v} h(t)=D_{0+}^{-v} h(t)=\frac{1}{\Gamma(v)} \int_{0}^{t}(t-s)^{\nu-1} h(s) d s
$$

provided that the right-hand side is pointwise defined on $[0,1]$.

Definition 2.2 $([1,3])$ The Riemann-Liouville fractional derivative of order $v>0$ of a continuous function $h:[0,1] \rightarrow \mathbb{R}$ is given by

$$
D_{0+}^{v} h(t)=\frac{1}{\Gamma(n-v)}\left(\frac{d}{d t}\right)^{n} \int_{0}^{t}(t-s)^{n-v-1} h(s) d s
$$

where $n=[v]+1, h \in A C^{n}[0,1]$, provided that the right-hand side is pointwise defined on $[0,1]$. 
Definition $2.3([1,3])$ The Caputo fractional derivative of order $v>0$ of a function $h$ : $[0,1] \rightarrow \mathbb{R}$ is given by

$$
{ }^{C} D_{0+}^{v} h(t)=\frac{1}{\Gamma(n-v)} \int_{0}^{t}(t-s)^{n-v-1} h^{(n)}(s) d s,
$$

where $n=[v]+1, h \in A C^{n}[0,1]$, provided that the right-hand side is pointwise defined on $[0,1]$.

Lemma 2.1 ([16]) Let $v>0$; then the differential equation

$$
{ }^{C} D_{0+}^{v} h(t)=0
$$

has solutions $h(t)=c_{0}+c_{1} t+c_{2} t^{2}+\cdots+c_{n-1} t^{n-1}, c_{i} \in \mathbb{R}, i=0,1,2, \ldots, n-1, n=[v]+1$.

Lemma $2.2([16])$ Let $v>0$; then

$$
I_{0+}^{\nu}{ }^{C} D_{0+}^{\nu} h(t)=h(t)+c_{0}+c_{1} t+c_{2} t^{2}+\cdots+c_{n-1} t^{n-1},
$$

for some $c_{i} \in \mathbb{R}, i=0,1,2, \ldots, n-1$, where $n=[v]+1$.

Lemma $2.3([1,3])$ If $v_{1}, v_{2}, v>0, t \in[0,1]$, and $h(t) \in L^{1}[0,1]$, then we have

$$
I_{0+}^{\nu_{1}} I_{0+}^{\nu_{2}} h(t)=I_{0+}^{\nu_{1}+\nu_{2}} h(t), \quad{ }^{C} D_{0+}^{\nu} I_{0+}^{\nu} h(t)=h(t) .
$$

Now let us recall some notations as regards the coincidence degree continuation theorem.

Let $X, Z$ be real Banach spaces. Consider the operation equation

$$
L u=N u,
$$

where $L: \operatorname{dom} L \subset X \rightarrow Z$ is a linear operator, $N: X \rightarrow Z$ is a nonlinear operator. If $\operatorname{dim} \operatorname{Ker} L=\operatorname{codim} \operatorname{Im} L<+\infty$ and $\operatorname{Im} L$ is closed in $Z$, then $L$ is called a Fredholm mapping of index zero. If $L$ is a Fredholm mapping of index zero, there exist linear continuous projectors $P: X \rightarrow X$ and $Q: Z \rightarrow Z$ such that $\operatorname{Ker} L=\operatorname{Im} P, \operatorname{Im} L=\operatorname{Ker} Q$, and $X=$ $\operatorname{Ker} L \oplus \operatorname{Ker} P, Z=\operatorname{Im} L \oplus \operatorname{Im} Q$. Then it follows that $L_{P}=\left.L\right|_{\operatorname{dom} L \cap \operatorname{Ker} P}: \operatorname{dom} L \cap \operatorname{Ker} P \rightarrow \operatorname{Im} L$ is invertible. We denote the inverse of this map by $K_{P}$. If $\bar{\Omega}$ is an open bounded subset of $X$, the map $N$ will be called $L$-compact on $\bar{\Omega}$ if $Q N(\bar{\Omega})$ is bounded and $K_{P, Q} N=$ $K_{P}(I-Q) N: \bar{\Omega} \rightarrow X$ is compact. For $\operatorname{Im} Q$ is isomorphic to $\operatorname{Ker} L$, there exists an isomorphism $J_{N L}: \operatorname{Im} Q \rightarrow \operatorname{Ker} L$. Then we shall give the coincidence degree continuation theorem, which is proved in [21].

Theorem 2.1 Let $L$ be a Fredholm operator of index zero and $N$ be L-compact on $\bar{\Omega}$, where $\Omega$ is an open bounded subset of $X$. Suppose that the following conditions are satisfied:

(i) $L x \neq \lambda N x$ for each $(x, \lambda) \in[(\operatorname{dom} L \backslash \operatorname{Ker} L) \cap \partial \Omega] \times(0,1)$;

(ii) $N x \notin \operatorname{Im} L$ for each $x \in \operatorname{Ker} L \cap \partial \Omega$;

(iii) $\operatorname{deg}\left(\left.J_{N L} Q N\right|_{\operatorname{Ker} L}, \Omega \cap \operatorname{Ker} L, 0\right) \neq 0$, where $Q: Z \rightarrow Z$ is a continuous projection as above with $\operatorname{Im} L=\operatorname{Ker} Q$ and $J_{N L}: \operatorname{Im} Q \rightarrow \operatorname{Ker} L$ is any isomorphism.

Then the equation $L x=N x$ has at least one solution in $\operatorname{dom} L \cap \bar{\Omega}$. 
Set $J_{0}=\left[0, t_{1}\right]$ and $J_{k}=\left(t_{k}, t_{k+1}\right], k=1,2, \ldots, p$. Then we shall introduce some function spaces in the following:

$$
P C(J, \mathbb{R})=\left\{x \mid x: J \rightarrow \mathbb{R}, x \in C\left(J_{k}\right) \text { and } x\left(t_{k}^{+}\right) \text {exists, } k=0,1,2, \ldots, p\right\},
$$

equipped with the norm

$$
\|x\|_{0}=\sup _{t \in J}|x(t)|
$$

and

$$
P C^{1}(J, \mathbb{R})=\left\{x \mid x \in P C(J, \mathbb{R}), x \in C^{1}\left(J_{k}\right) \text { and } x^{\prime}\left(t_{k}^{+}\right) \text {exists, } k=0,1,2, \ldots, p\right\},
$$

equipped with the norm

$$
\|x\|_{1}=\sup _{t \in J}|x(t)|+\sup _{t \in J}\left|x^{\prime}(t)\right| .
$$

Obviously, $P C(J, \mathbb{R})$ and $P C^{1}(J, \mathbb{R})$ are Banach spaces.

Define $X=P C^{1}(J, \mathbb{R})$ and $Z=P C(J, \mathbb{R}) \times \mathbb{R}^{2 p}$ with the norm

$$
\|z\|_{2}=\sup _{t \in J}|x(t)|+\sum_{i=1}^{2 p}\left|z_{i}\right|, \quad \forall z=\left(x, z_{1}, z_{2}, \ldots, z_{2 p}\right) \in Z
$$

where $x \in P C(J, \mathbb{R}),\left(z_{1}, z_{2}, \ldots, z_{2 p}\right) \in \mathbb{R}^{2 p}$. It is easy to verify that $\left(Z,\|\cdot\|_{2}\right)$ is a Banach space.

Let

$$
\begin{aligned}
& \operatorname{dom} L=\left\{x \mid x \in X,{ }^{C} D_{0+}^{\alpha} u(t) \in P C(J, \mathbb{R}), u(0)=0, u^{\prime}(1)=\sum_{j=1}^{m-2} \sigma_{j} u^{\prime}\left(\xi_{j}\right)\right\}, \\
& L: \operatorname{dom} L \rightarrow Z, \quad u \rightarrow\left({ }^{C} D_{0+}^{\alpha} u(t), \Delta u\left(t_{1}\right), \ldots, \Delta u\left(t_{p}\right), \Delta u^{\prime}\left(t_{1}\right), \ldots, \Delta u^{\prime}\left(t_{p}\right)\right)
\end{aligned}
$$

and

$$
N: X \rightarrow Z, \quad u \rightarrow\left(f\left(t, u(t), u^{\prime}(t)\right), A_{1}, \ldots, A_{p}, B_{1}, \ldots, B_{p}\right)
$$

where $A_{k}=I_{k}\left(u\left(t_{k}^{-}\right), u^{\prime}\left(t_{k}^{-}\right)\right), B_{k}=J_{k}\left(u\left(t_{k}^{-}\right), u^{\prime}\left(t_{k}^{-}\right)\right), k=1,2, \ldots, p$.

Then the multi-point boundary value problem can be written

$$
L u=N u, \quad u \in \operatorname{dom} L .
$$

At the end of the section we give a method for determining the compactness of a set in $X$.

Lemma 2.4 $\mathcal{U}$ is a relatively compact set in $X$ if and only if the following conditions are satisfied: 
(a) $\mathcal{U}$ is uniformly bounded, that is, there exists a constant $R>0$, such that for each $u \in \mathcal{U},\|u\|_{1} \leq R$.

(b) $\forall \varepsilon>0$, there exists $\delta=\delta(\varepsilon)>0$, such that

$$
\begin{gathered}
\left|u\left(t_{1}\right)-u\left(t_{2}\right)\right|<\varepsilon, \quad\left|u^{\prime}\left(t_{1}\right)-u^{\prime}\left(t_{2}\right)\right|<\varepsilon, \\
\text { for } \forall t_{1}, t_{2} \in J_{k}, k=0,1,2, \ldots, p,\left|t_{1}-t_{2}\right|<\delta, \forall u \in \mathcal{U} .
\end{gathered}
$$

Proof Analogous to the proof of the Lemma 2.2 in [17], we can prove the results. Here, we omit the details.

\section{Main results}

In this section, we will establish the existence theorem for the impulsive fractional differential equation (1.1). In order to prove our main results, we need the following lemmas.

Lemma 3.1 Suppose that $g \in P C(J, \mathbb{R})$ and $\sum_{j=1}^{m-2} \sigma_{j}=1$. A function $u \in X$ is a solution of the impulsive differential equation of fractional order

$$
\left\{\begin{array}{l}
{ }^{C} D_{0+}^{\alpha} u(t)=g(t), \quad t \in J^{\prime}, \\
\Delta u\left(t_{k}\right)=a_{k}, \quad k=1,2, \ldots, p, \\
\Delta u^{\prime}\left(t_{k}\right)=b_{k}, \quad k=1,2, \ldots, p, \\
u(0)=0, \quad u^{\prime}(1)=\sum_{j=1}^{m-2} \sigma_{j} u^{\prime}\left(\xi_{j}\right),
\end{array}\right.
$$

if and only if

$$
u(t)=\sum_{i=1}^{k} a_{i}-\sum_{i=1}^{k} b_{i} t_{i}+\left(c+\sum_{i=1}^{k} b_{i}\right) t+\frac{1}{\Gamma(\alpha)} \int_{0}^{t}(t-s)^{\alpha-1} g(s) d s, \quad t \in J_{k},
$$

where $k=0,1,2, \ldots, p$ and $c \in \mathbb{R}$, and

$$
\begin{aligned}
& \sum_{i=1}^{p} b_{i}-\sum_{j=1}^{m-2} \sigma_{j}\left(\sum_{t_{i}<\xi_{j}} b_{i}\right) \\
& \quad+\frac{1}{\Gamma(\alpha-1)}\left[\int_{0}^{1}(1-s)^{\alpha-2} g(s) d s-\sum_{j=1}^{m-2} \sigma_{j}\left(\int_{0}^{\xi_{j}}\left(\xi_{j}-s\right)^{\alpha-2} g(s) d s\right)\right]=0 .
\end{aligned}
$$

Proof In view of Lemma 2.7 in [9] or Lemma 4.1 in [15], we can get the conclusions by applying Lemma 2.2 and Lemma 2.3 .

Lemma 3.2 Assume that $\sum_{j=1}^{m-2} \sigma_{j}=1$ and

$$
\Lambda_{0}:=\frac{1}{\Gamma(\alpha)}\left(1-\sum_{j=1}^{m-2} \sigma_{j} \xi_{j}^{\alpha-1}\right) \neq 0
$$

Then $L$ is a Fredholm mapping of index zero. Moreover,

$$
\operatorname{Ker} L=\{u \mid u=c t, c \in \mathbb{R}\} \subset X
$$


and

$$
\begin{aligned}
\operatorname{Im} L & =\left\{z \mid z=\left(g, a_{1}, \ldots, a_{p}, b_{1}, \ldots, b_{p}\right) \in Z \text { and } g \text { satisfies the condition (3.3) }\right\} \\
& \subset Z
\end{aligned}
$$

Proof Taking into account Lemma 2.1 and the definition of $L$, we can get the result (3.4) easily. Further, Lemma 3.1 implies (3.5). Now, let us focus on the proof that $L$ is a Fredholm mapping of index zero.

Define an auxiliary operator $Q_{1}: Z \rightarrow \mathbb{R}$ as follows:

$$
\begin{aligned}
Q_{1} z= & \sum_{i=1}^{p} b_{i}-\sum_{j=1}^{m-2} \sigma_{j}\left(\sum_{t_{i}<\xi_{j}} b_{i}\right) \\
& +\frac{1}{\Gamma(\alpha-1)}\left[\int_{0}^{1}(1-s)^{\alpha-2} g(s) d s-\sum_{j=1}^{m-2} \sigma_{j}\left(\int_{0}^{\xi_{j}}\left(\xi_{j}-s\right)^{\alpha-2} g(s) d s\right)\right],
\end{aligned}
$$

where $z=\left(g, a_{1}, \ldots, a_{p}, b_{1}, \ldots, b_{p}\right) \in Z$. It is obvious that $Q_{1}$ is a continuous linear mapping.

Take the mapping $Q: Z \rightarrow Z$ defined by

$$
Q z=\left(\frac{Q_{1} z}{\Lambda_{0}}, 0, \ldots, 0\right)
$$

where $z=\left(g, a_{1}, \ldots, a_{p}, b_{1}, \ldots, b_{p}\right) \in Z$ and $(0, \ldots, 0) \in \mathbb{R}^{2 p}$. Evidently, $\operatorname{Ker} Q=\operatorname{Im} L$ and

$$
\operatorname{Im} Q=\left\{(c, 0, \ldots, 0) \in Z \mid c \in \mathbb{R},(0, \ldots, 0) \in \mathbb{R}^{2 p}\right\}
$$

and $Q: Z \rightarrow Z$ is a continuous linear projector. In fact, for an arbitrary $z \in Z$, we have

$$
Q_{1}(Q z)=Q_{1}\left(\frac{Q_{1} z}{\Lambda_{0}}, 0, \ldots, 0\right)=\frac{Q_{1} z}{\Lambda_{0}} \Lambda_{0}=Q_{1} z
$$

and

$$
Q^{2} z=Q(Q z)=\left(\frac{Q_{1}(Q z)}{\Lambda_{0}}, 0, \ldots, 0\right)=\left(\frac{Q_{1} z}{\Lambda_{0}}, 0, \ldots, 0\right)=Q z
$$

that is to say, $Q: Z \rightarrow Z$ is idempotent.

Let $z=z-Q z+Q z=(I-Q) z+Q z$, where $z$ is an arbitrary element in $Z$. Since $Q z \in \operatorname{Im} Q$ and $(I-Q) z \in \operatorname{Ker} Q$, we obtain $Z=\operatorname{Im} Q+\operatorname{Ker} Q$. Take $z_{0} \in \operatorname{Im} Q \cap \operatorname{Ker} Q$. Then $z_{0}$ can be written as $z_{0}=\left(c_{0}, 0, \ldots, 0\right)$, where $c_{0} \in \mathbb{R},(0, \ldots, 0) \in \mathbb{R}^{2 p}$, for $z_{0} \in \operatorname{Im} Q$. Thus we have $Q_{1}\left(z_{0}\right)=c_{0} \Lambda_{0}=0$, which implies that $c_{0}=0$ and $z_{0}=\theta$. Hence $\operatorname{Im} Q \cap \operatorname{Ker} Q=\{\theta\}$, where we denote $\theta$ the zero element in $Z$. Then we get $Z=\operatorname{Im} Q \oplus \operatorname{Ker} Q=\operatorname{Im} Q \oplus \operatorname{Im} L$.

Now, $\operatorname{dim} \operatorname{Ker} L=1=\operatorname{dim} \operatorname{Im} Q=\operatorname{codim} \operatorname{Ker} Q=\operatorname{codim} \operatorname{Im} L<+\infty$, and noting that $\operatorname{Im} L$ is closed in $Z, L$ is a Fredholm mapping of index zero.

Let $P: X \rightarrow X$ be defined by

$$
(P u)(t)=u^{\prime}(0) t, \quad t \in J, u \in X .
$$


Clearly, $P: X \rightarrow X$ is a linear continuous projector and

$$
\operatorname{Im} P=\{u \mid u=c t, c \in \mathbb{R}\}=\operatorname{Ker} L .
$$

Also, proceeding as in the proof of Lemma 3.2, we can show that $X=\operatorname{Im} P \oplus \operatorname{Ker} P=$ $\operatorname{Ker} L \oplus \operatorname{Ker} P$.

Consider the mapping $K_{P}: \operatorname{Im} L \rightarrow \operatorname{dom} L \cap \operatorname{Ker} P$ :

$$
\left(K_{P} z\right)(t)=\sum_{i=1}^{k} a_{i}-\sum_{i=1}^{k} b_{i} t_{i}+\frac{1}{\Gamma(\alpha)} \int_{0}^{t}(t-s)^{\alpha-1} g(s) d s, \quad t \in J_{k},
$$

where $k=0,1,2, \ldots, p$ and $z=\left(g, a_{1}, \ldots, a_{p}, b_{1}, \ldots, b_{p}\right) \in \operatorname{Im} L$.

Note that

$$
\left(K_{P} L\right) u=K_{P}(L u)=u, \quad \forall u \in \operatorname{dom} L \cap \operatorname{Ker} P
$$

and

$$
\left(L K_{P}\right) z=L\left(K_{P} z\right)=z, \quad \forall z \in \operatorname{Im} L .
$$

Thus, $K_{P}=\left(L_{P}\right)^{-1}$, where $L_{P}=\left.L\right|_{\operatorname{dom} L \cap \operatorname{Ker} P}: \operatorname{dom} L \cap \operatorname{Ker} P \rightarrow \operatorname{Im} L$.

Lemma 3.3 For each $z=\left(g, a_{1}, \ldots, a_{p}, b_{1}, \ldots, b_{p}\right) \in \operatorname{Im} L$, we have

$$
\left\|K_{P} z\right\|_{1} \leq\left(1+\frac{1}{\Gamma(\alpha)}\right)\|z\|_{2} .
$$

Proof For each $z=\left(g, a_{1}, \ldots, a_{p}, b_{1}, \ldots, b_{p}\right) \in \operatorname{Im} L$ and $t \in J_{k}, k=0,1,2, \ldots, p$, we have

$$
\begin{aligned}
\left|\left(K_{P} z\right)(t)\right| & =\left|\sum_{i=1}^{k} a_{i}-\sum_{i=1}^{k} b_{i} t_{i}+\frac{1}{\Gamma(\alpha)} \int_{0}^{t}(t-s)^{\alpha-1} g(s) d s\right| \\
& \leq \sup _{t \in J}|g(t)| \cdot\left|\frac{1}{\Gamma(\alpha)} \int_{0}^{t}(t-s)^{\alpha-1} d s\right|+\sum_{i=1}^{k}\left|a_{i}\right|+\sum_{i=1}^{k}\left|b_{i}\right| \\
& =\sup _{t \in J}|g(t)| \cdot \frac{1}{\Gamma(\alpha+1)} t^{\alpha}+\sum_{i=1}^{k}\left|a_{i}\right|+\sum_{i=1}^{k}\left|b_{i}\right| \\
& \leq \sup _{t \in J}|g(t)|+\sum_{i=1}^{p}\left|b_{i}\right|+\sum_{i=1}^{p}\left|a_{i}\right|=\|z\|_{2}
\end{aligned}
$$

and

$$
\left|\left(K_{P} z\right)^{\prime}(t)\right|=\left|\frac{1}{\Gamma(\alpha-1)} \int_{0}^{t}(t-s)^{\alpha-2} g(s) d s\right| \leq \sup _{t \in J}|g(t)| \cdot \frac{1}{\Gamma(\alpha)} t^{\alpha-1} \leq \frac{1}{\Gamma(\alpha)}\|z\|_{2} .
$$

Hence,

$$
\left\|K_{P} z\right\|_{1}=\sup _{t \in J}\left|\left(K_{P} z\right)(t)\right|+\sup _{t \in J}\left|\left(K_{P} z\right)^{\prime}(t)\right| \leq\left(1+\frac{1}{\Gamma(\alpha)}\right)\|z\|_{2} .
$$


Lemma 3.4 Let $f:[0,1] \times \mathbb{R} \times \mathbb{R} \rightarrow \mathbb{R}$ and $I_{k}, J_{k}: \mathbb{R} \times \mathbb{R} \rightarrow \mathbb{R}(k=1,2, \ldots, p)$ are continuous. Then $K_{P, Q} N=K_{P}(I-Q) N: X \rightarrow X$ is completely continuous.

Proof By virtue of Lemma 2.4, we can conclude that the claim of the lemma is true.

Next, let us list the assumptions that will be used in the rest of the section.

$\left(\mathrm{H}_{1}\right) f:[0,1] \times \mathbb{R} \times \mathbb{R} \rightarrow \mathbb{R}$ is continuous, and there exist three nonnegative functions $\beta_{1}, \beta_{2}, \beta_{3} \in P C(J, \mathbb{R})$ such that for all $t \in J$ and $(x, y) \in \mathbb{R}^{2}$, we have

$$
|f(t, x, y)| \leq \beta_{1}(t)|x|+\beta_{2}(t)|y|+\beta_{3}(t) .
$$

$\left(\mathrm{H}_{2}\right)$ There exist $M_{i} \geq 0, N_{i} \geq 0, D_{i} \geq 0(i=1,2, \ldots, 2 p)$ such that

$$
\left|I_{k}(x, y)\right| \leq M_{k}|x|+N_{k}|y|+D_{k}, \quad\left|J_{k}(x, y)\right| \leq M_{p+k}|x|+N_{p+k}|y|+D_{p+k},
$$

where $k=1,2, \ldots, p, \forall(x, y) \in \mathbb{R}^{2}$.

$\left(\mathrm{H}_{3}\right)$

$$
0 \leq\left(1+\frac{1}{\Gamma(\alpha)}\right)\left(\eta_{1}+\sum_{i=1}^{2 p}\left(M_{i}+N_{i}\right)\right)<1,
$$

where $\eta_{1}=\sup _{t \in J}\left|\beta_{1}(t)\right|+\sup _{t \in J}\left|\beta_{2}(t)\right|$.

$\left(\mathrm{H}_{4}\right)$ There exists a constant $T_{1}>0$ such that

$$
Q_{1}(N u) \neq 0,
$$

for each $u \in \operatorname{dom} L \backslash \operatorname{Ker} L$ satisfying $\left|u^{\prime}(0)\right|>T_{1}$.

$\left(\mathrm{H}_{5}\right)$ There exists a positive constant $S$ such that for any $c \in \mathbb{R}$, if $|c|>S$, then either

$$
c \Lambda_{0} Q_{1}(N(c t))<0,
$$

or else

$$
c \Lambda_{0} Q_{1}(N(c t))>0 .
$$

Theorem 3.1 Let $\sum_{j=1}^{m-2} \sigma_{j}=1, \Lambda_{0} \neq 0, f:[0,1] \times \mathbb{R} \times \mathbb{R} \rightarrow \mathbb{R}$ and $I_{k}, J_{k}: \mathbb{R} \times \mathbb{R} \rightarrow \mathbb{R}$ $(k=1,2, \ldots, p)$ are continuous. Assume that the hypotheses $\left(\mathrm{H}_{1}\right)-\left(\mathrm{H}_{5}\right)$ all hold. Then the problem (1.1) has at least one solution in $\operatorname{dom} L$.

Proof The proof consists of four main steps as follows.

(1) Set $\Omega_{1}=\{u \in \operatorname{dom} L \backslash \operatorname{Ker} L \mid L u=\lambda N u, \lambda \in[0,1]\}$ and proof of $\Omega_{1}$ is bounded.

(2) Set $\Omega_{2}=\{u \in \operatorname{Ker} L \mid N u \in \operatorname{Im} L\}$ and proof of $\Omega_{2}$ is bounded.

(3) If (3.14) holds, we set $\Omega_{3}=\left\{u \in \operatorname{Ker} L \mid-\lambda u+(1-\lambda) J_{N L} Q N u=0, \lambda \in[0,1]\right\}$; if (3.15) holds, we set $\Omega_{3}=\left\{u \in \operatorname{Ker} L \mid \lambda u+(1-\lambda) J_{N L} Q N u=0, \lambda \in[0,1]\right\}$, where $J_{N L}: \operatorname{Im} Q \rightarrow \operatorname{Ker} L$ is a linear isomorphism defined as

$$
J_{N L}(c, 0, \ldots, 0)=c t, \quad(c, 0, \ldots, 0) \in \operatorname{Im} Q, t \in[0,1] .
$$

Then proof of $\Omega_{3}$ is bounded. 
(4) Let $\Omega$ be a bounded open set such that $\Omega \supset \bigcup_{i=1}^{3} \bar{\Omega}_{i}$ and prove that

$$
\operatorname{deg}\left(\left.J_{N L} Q N\right|_{\operatorname{Ker} L}, \Omega \cap \operatorname{Ker} L, 0\right) \neq 0 .
$$

Now, let us prove the steps one by one.

Step 1: Take $u \in \Omega_{1}$, then $u \in \operatorname{dom} L \backslash \operatorname{Ker} L$ and $L u=\lambda N u$, so $\lambda \neq 0$ and $N u \in \operatorname{Im} L=$ $\operatorname{Ker} Q \subset Z$. Hence, $Q(N u)=\theta$, that is, $Q_{1}(N u)=0$. From $\left(\mathrm{H}_{4}\right)$, we have $\left|u^{\prime}(0)\right| \leq T_{1}$.

Again, for $u \in \Omega_{1}$, we get

$$
\begin{aligned}
\|P u\|_{1} & =\sup _{t \in J}|P u(t)|+\sup _{t \in J}\left|(P u)^{\prime}(t)\right| \\
& =\sup _{t \in J}\left|u^{\prime}(0) t\right|+\sup _{t \in J}\left|u^{\prime}(0)\right|=2\left|u^{\prime}(0)\right| \leq 2 T_{1} .
\end{aligned}
$$

In view of $(I-P) u \in \operatorname{dom} L \cap \operatorname{Ker} P$, by (3.8) and Lemma 3.3, we have

$$
\begin{aligned}
\|(I-P) u\|_{1} & =\left\|K_{p} L(I-P) u\right\|_{1} \leq\left(1+\frac{1}{\Gamma(\alpha)}\right)\|L(I-P) u\|_{2} \\
& =\left(1+\frac{1}{\Gamma(\alpha)}\right)\|L u\|_{2} \leq\left(1+\frac{1}{\Gamma(\alpha)}\right)\|N u\|_{2} .
\end{aligned}
$$

Combining (3.17) and (3.18), we can obtain

$$
\begin{aligned}
\|u\|_{1} & =\|u-P u+P u\|_{1} \leq\|P u\|_{1}+\|(I-P) u\|_{1} \\
& \leq 2 T_{1}+\left(1+\frac{1}{\Gamma(\alpha)}\right)\|N u\|_{2} .
\end{aligned}
$$

From $\left(\mathrm{H}_{1}\right)$, for each $u \in \Omega_{1}$, we have

$$
\begin{aligned}
\left|f\left(t, u(t), u^{\prime}(t)\right)\right| & \leq \beta_{1}(t)|u(t)|+\beta_{2}(t)\left|u^{\prime}(t)\right|+\beta_{3}(t) \\
& \leq \sup _{t \in J}\left|\beta_{1}(t)\right| \cdot|u(t)|+\sup _{t \in J}\left|\beta_{2}(t)\right| \cdot\left|u^{\prime}(t)\right|+\sup _{t \in J}\left|\beta_{3}(t)\right| \\
& \leq \eta_{1}\|u\|_{1}+\eta_{2}
\end{aligned}
$$

where we denote $\eta_{2}=\sup _{t \in J}\left|\beta_{3}(t)\right|$.

From $\left(\mathrm{H}_{2}\right)$, for each $u \in \Omega_{1}$, we get

$$
\begin{aligned}
\left|I_{k}\left(u\left(t_{k}^{-}\right), u^{\prime}\left(t_{k}^{-}\right)\right)\right| & \leq M_{k}\left|u\left(t_{k}^{-}\right)\right|+N_{k}\left|u^{\prime}\left(t_{k}^{-}\right)\right|+D_{k} \\
& \leq\left(M_{k}+N_{k}\right)\|u\|_{1}+D_{k}
\end{aligned}
$$

and

$$
\begin{aligned}
\left|J_{k}\left(u\left(t_{k}^{-}\right), u^{\prime}\left(t_{k}^{-}\right)\right)\right| & \leq M_{p+k}\left|u\left(t_{k}^{-}\right)\right|+N_{p+k}\left|u^{\prime}\left(t_{k}^{-}\right)\right|+D_{p+k} \\
& \leq\left(M_{p+k}+N_{p+k}\right)\|u\|_{1}+D_{p+k},
\end{aligned}
$$

where $k=1,2, \ldots, p$. 
Combining (3.20), (3.21), and (3.22), we obtain

$$
\begin{aligned}
\|N u\|_{2} & =\sup _{t \in J}\left|f\left(t, u(t), u^{\prime}(t)\right)\right|+\sum_{i=1}^{p}\left|I_{k}\left(u\left(t_{k}^{-}\right), u^{\prime}\left(t_{k}^{-}\right)\right)\right|+\sum_{i=1}^{p}\left|J_{k}\left(u\left(t_{k}^{-}\right), u^{\prime}\left(t_{k}^{-}\right)\right)\right| \\
& \leq \eta_{1}\|u\|_{1}+\eta_{2}+\left(\sum_{i=1}^{2 p}\left(M_{i}+N_{i}\right)\right)\|u\|_{1}+\sum_{i=1}^{2 p} D_{i} \\
& =\left(\eta_{1}+\sum_{i=1}^{2 p}\left(M_{i}+N_{i}\right)\right)\|u\|_{1}+\sum_{i=1}^{2 p} D_{i}+\eta_{2} .
\end{aligned}
$$

Thus, by $\left(\mathrm{H}_{3}\right)$, (3.19), and (3.23), we can derive

$$
\|u\|_{1} \leq \frac{2 T_{1}+(1+1 / \Gamma(\alpha)) \sum_{i=1}^{2 p} D_{i}+(1+1 / \Gamma(\alpha)) \eta_{2}}{1-(1+1 / \Gamma(\alpha))\left(\eta_{1}+\sum_{i=1}^{2 p}\left(M_{i}+N_{i}\right)\right)}
$$

which clearly shows that $\Omega_{1}$ is bounded.

Step 2: Let $u \in \Omega_{2}$, then $u \in \operatorname{Ker} L$ and $u=c t, c \in \mathbb{R}, t \in J$. Since $N u \in \operatorname{Im} L=\operatorname{Ker} Q$, we have $Q(N u)=\theta$, that is, $Q_{1}(N(c t))=0$. Taking into account $\left(\mathrm{H}_{5}\right),|c| \leq S$, which implies that $\Omega_{2}$ is bounded.

Step 3: Without loss of generality, in the following part of the proof, we assume that (3.14) holds in $\left(\mathrm{H}_{5}\right)$. Then we set $\Omega_{3}=\left\{u \in \operatorname{Ker} L \mid-\lambda u+(1-\lambda) J_{N L} Q N u=0, \lambda \in[0,1]\right\}$. For $u \in \Omega_{3}$, then we have $u=c t, c \in \mathbb{R}, t \in[0,1]$, and $\lambda u=(1-\lambda) J_{N L} Q N u$. Thus,

$$
\lambda c t=(1-\lambda) \frac{Q_{1}(N(c t))}{\Lambda_{0}} t .
$$

Therefore, via $\left(\mathrm{H}_{5}\right)$ and (3.14), we have $|c| \leq S$, which shows that $\Omega_{3}$ is bounded.

Step 4: Let $\Omega$ be a bounded open set such that $\Omega \supset \bigcup_{i=1}^{3} \bar{\Omega}_{i}$. The operator $N$ is $L$-compact on $\bar{\Omega}$ due to the fact that $Q N(\bar{\Omega})$ is bounded and $K_{P, Q} N=K_{P}(I-Q) N: \bar{\Omega} \rightarrow X$ is compact by Lemma 3.4. Then by Step 1 and Step 2, we have

(i) $L u \neq \lambda N u$ for each $(u, \lambda) \in[(\operatorname{dom} L \backslash \operatorname{Ker} L) \cap \partial \Omega] \times(0,1)$;

(ii) $N u \notin \operatorname{Im} L$ for each $u \in \operatorname{Ker} L \cap \partial \Omega$.

Define $H(u, \lambda)=-\lambda I u+(1-\lambda) J_{N L} Q N u$, where $I$ is the identity operator in $X$. According to the arguments in Step 3, we have

$$
H(u, \lambda) \neq 0, \quad \forall u \in \operatorname{Ker} L \cap \partial \Omega,
$$

and therefore, via the homotopy property of degree, we obtain

$$
\begin{aligned}
\operatorname{deg}\left(\left.J_{N L} Q N\right|_{\operatorname{Ker} L}, \Omega \cap \operatorname{Ker} L, 0\right) & =\operatorname{deg}(H(\cdot, 0), \Omega \cap \operatorname{Ker} L, 0) \\
& =\operatorname{deg}(H(\cdot, 1), \Omega \cap \operatorname{Ker} L, 0) \\
& =\operatorname{deg}(-I, \Omega \cap \operatorname{Ker} L, 0) \\
& =-1,
\end{aligned}
$$

which verifies the condition (iii) of Theorem 2.1. Then, applying Theorem 2.1, we conclude that the problem (1.1) has at least one solution in $\operatorname{dom} L \cap \bar{\Omega}$. The proof is complete. 
Corollary 3.1 If the conditions $\left(\mathrm{H}_{3}\right)$ and $\left(\mathrm{H}_{4}\right)$ are replaced by:

$\left(\mathrm{H}_{3}^{*}\right)$

$$
0 \leq\left(1+\frac{3}{\Gamma(\alpha)}\right)\left(\eta_{1}+\sum_{i=1}^{2 p}\left(M_{i}+N_{i}\right)\right)<1 .
$$

$\left(\mathrm{H}_{4}^{*}\right)$ There exists a constant $T_{1}^{*}>0$ such that

$$
Q_{1}(N u) \neq 0
$$

for each $u \in \operatorname{dom} L \backslash \operatorname{Ker} L$ satisfying $\left|u^{\prime}(t)\right|>T_{1}^{*}$.

Then the problem (1.1) has at least one solution in $\operatorname{dom} L$.

Theorem 3.2 Let $\sum_{j=1}^{m-2} \sigma_{j}=1, \sigma_{j}>0(j=1,2, \ldots, m-2), f:[0,1] \times \mathbb{R} \times \mathbb{R} \rightarrow \mathbb{R}$ and $I_{k}, J_{k}$ : $\mathbb{R} \times \mathbb{R} \rightarrow \mathbb{R}(k=1,2, \ldots, p)$ are continuous. Suppose that $\left(\mathrm{H}_{2}\right)$ and the following conditions are satisfied:

$\left(\mathrm{H}_{3}^{\prime}\right)$

$$
0 \leq\left(1+\frac{3}{\Gamma(\alpha)}\right)\left(\sum_{i=1}^{2 p}\left(M_{i}+N_{i}\right)\right)<1
$$

$\left(\mathrm{H}_{6}\right)$ There exists a constant $T_{3}>0$, such that for any $|y|>T_{2}$, we have

$$
\gamma_{1}(t) T_{3} \leq f(t, x, y) \leq \gamma_{2}(t) T_{3},
$$

where $\gamma_{1}(t), \gamma_{2}(t) \in C[0,1]$ and $\gamma_{2}(t) \geq \gamma_{1}(t) \geq 0$.

$\left(\mathrm{H}_{7}\right)$ For $\forall(x, y) \in \mathbb{R}^{2}, J_{k}(x, y) \geq 0, k=1,2, \ldots, p$.

$\left(\mathrm{H}_{8}\right)$

$$
\int_{0}^{1}(1-s)^{\alpha-2} \gamma_{1}(s) d s-\sum_{j=1}^{m-2} \sigma_{j}\left(\int_{0}^{\xi_{j}}\left(\xi_{j}-s\right)^{\alpha-2} \gamma_{2}(s) d s\right)>0 .
$$

Then the problem (1.1) has at least one solution in $\operatorname{dom} L$.

Proof In view of $\sigma_{j}>0(j=1,2, \ldots, m-2)$ and $\left(\mathrm{H}_{7}\right)$, we have $\Lambda_{0}>0$.

First, let us set $\Omega_{1}=\{u \in \operatorname{dom} L \backslash \operatorname{Ker} L \mid L u=\lambda N u, \lambda \in[0,1]\}$. Hence, for each $u \in \Omega_{1}$, we have $Q(N u)=\theta$, that is, $Q_{1}(N u)=0$. We claim that there exists $t_{1} \in[0,1]$ such that $\left|u^{\prime}\left(t_{1}\right)\right| \leq T_{2}, t \in J$.

In fact, if we assume that $\left|u^{\prime}(t)\right|>T_{2}$, in view of $\sigma_{j}>0$, $\left(\mathrm{H}_{6}\right)$, and $\left(\mathrm{H}_{8}\right)$, we can get $Q_{1}(\mathrm{Nu})>$ 0 , which contradicts $Q_{1}(N u)=0$. Thus, the claim that there exists $t_{1} \in[0,1]$ such that $\left|u^{\prime}\left(t_{1}\right)\right| \leq T_{2}$ is true.

If $t_{1}=0,\left|u^{\prime}(0)\right| \leq T_{2}$. If $t_{1}>0$, we have

$$
\left|u^{\prime}(0)\right| \leq T_{2}+\frac{1}{\Gamma(\alpha)}\|N u\|_{2} .
$$


Since

$$
u^{\prime \prime}(t)={ }^{C} D_{0+}^{2-\alpha}\left({ }^{C} D_{0+}^{\alpha} u(t)\right)
$$

we have

$$
\begin{aligned}
\left|\int_{0}^{t_{1}} u^{\prime \prime}(s) d s\right| & =\left|I_{0+}^{1}{ }^{C} D_{0+}^{2-\alpha}\left({ }^{C} D_{0+}^{\alpha} u\left(t_{1}\right)\right)\right| \\
& =\left|I_{0+}^{\alpha-1}(L u)\left(t_{1}\right)\right| \\
& =\left|\frac{1}{\Gamma(\alpha-1)} \int_{0}^{t_{1}}\left(t_{1}-s\right)^{\alpha-2}\left({ }^{C} D_{0+}^{\alpha} u(s)\right) d s\right| \\
& \leq\|L u\|_{2} \cdot \frac{1}{\Gamma(\alpha-1)} \int_{0}^{t_{1}}\left(t_{1}-s\right)^{\alpha-2} d s \\
& \leq\|L u\|_{2} \cdot \frac{1}{\Gamma(\alpha)} \leq \frac{1}{\Gamma(\alpha)}\|N u\|_{2} .
\end{aligned}
$$

Thus,

$$
\left|u^{\prime}(0)\right|=\left|u^{\prime}\left(t_{1}\right)-\int_{0}^{t_{1}} u^{\prime \prime}(s) d s\right| \leq\left|u^{\prime}\left(t_{1}\right)\right|+\left|\int_{0}^{t_{1}} u^{\prime \prime}(s) d s\right| \leq T_{2}+\frac{1}{\Gamma(\alpha)}\|N u\|_{2} .
$$

Similar to the discussion in Theorem 3.1, we can get

$$
\|u\|_{1} \leq \frac{2 T_{2}+T_{3}(1+3 / \Gamma(\alpha)) \max _{t \in[0,1]} \gamma_{2}(t)+(1+3 / \Gamma(\alpha)) \sum_{i=1}^{2 p} D_{i}}{1-(1+3 / \Gamma(\alpha))\left(\sum_{i=1}^{2 p}\left(M_{i}+N_{i}\right)\right)} .
$$

Therefore, $\Omega_{1}$ is bounded.

Also, $\Lambda_{0}>0,\left(\mathrm{H}_{6}\right)$, and $\left(\mathrm{H}_{8}\right)$ imply that $\left(\mathrm{H}_{5}\right)$ is satisfied. Then, proceeding with the proof of the theorem similar to the proof of Theorem 3.1, we can derive the conclusion.

\section{Examples}

To illustrate our main results, we shall present an example.

\section{Example 4.1}

$$
\left\{\begin{array}{l}
{ }^{C} D_{0+}^{1.8} u(t)=f\left(t, u(t), u^{\prime}(t)\right), \quad t \in J^{\prime}, \\
\Delta u\left(t_{k}\right)=l, \quad k=1,2,3 \\
\Delta u^{\prime}\left(t_{k}\right)=J_{k}, \quad k=1,2,3, \\
u(0)=0, \quad u^{\prime}(1)=\sum_{j=1}^{3} \sigma_{j} u^{\prime}\left(\xi_{j}\right)
\end{array}\right.
$$

where

$$
f(t, x, y)=\frac{t^{\alpha-1}}{20} \frac{|y|}{1+|y|}\left(1+e^{-|x|}-\frac{\sin ^{2} t}{1+y^{2}}\right), \quad t \in[0,1],(x, y) \in \mathbb{R}^{2}
$$

and

$$
J_{k}(x, y)=\frac{1}{k+1}
$$


and $l \in \mathbb{R}, l>0, t_{1}=0.25, t_{2}=0.5, t_{3}=0.75, \xi_{1}=0.2, \xi_{2}=0.4, \xi_{3}=0.6, \sigma_{1}=0.2, \sigma_{2}=0.3$, $\sigma_{3}=0.5, k_{1}=0, k_{2}=1, k_{3}=2$.

From the above conditions, we can find that $\left(\mathrm{H}_{2}\right),\left(\mathrm{H}_{3}^{\prime}\right)$, and $\left(\mathrm{H}_{7}\right)$ hold. Noting that $\alpha=$ $1.8, p=3, m=5, \sum_{i=1}^{3} \sigma_{i}=1$, for each $|y|>2$, we have

$$
\gamma_{1}(t) \leq f(t, x, y) \leq \gamma_{2}(t)
$$

where $\gamma_{2}=t^{\alpha-1} / 10$, and $\gamma_{1}=t^{\alpha-1} / 30$, so $\left(\mathrm{H}_{6}\right)$ is satisfied. Also we can certify that $\left(\mathrm{H}_{8}\right)$ holds, too.

To sum up the points which we have just indicated, by Theorem 3.2, we can conclude that the problem (4.1) has at least one solution.

\section{Competing interests}

The authors declare that they have no competing interests.

\section{Authors' contributions}

All authors contributed equally to the writing of this paper. All authors read and approved the final manuscript.

\section{Author details}

${ }^{1}$ Department of Mathematics, China University of Mining and Technology, Xuzhou, 221116, P.R. China. ${ }^{2}$ School of Business, Central South University, Changsha, Hunan 410083, P.R. China. ${ }^{3}$ School of Mathematics and Statistics, Central South University, Changsha, Hunan 410083, P.R. China.

\section{Acknowledgements}

This research was supported by the Fundamental Research Funds for the Central Universities (2014QNA52) and Natural Science Foundation of Jiangsu Province of China (BK20140176). The research is also supported by the TianYuan Special Funds of the National Natural Science Foundation of China (Grant No. 11426211).

Received: 18 September 2014 Accepted: 12 November 2014 Published online: 09 December 2014

\section{References}

1. Kilbas, AA, Srivastava, HM, Trujillo, JJ: Theory and Applications of Fractional Differential Equations. Elsevier, Amsterdam (2006)

2. Lakshmikantham, V, Leela, S, Vasundhara Devi, J: Theory of Fractional Dynamic Systems. Cambridge Academic Publishers, Cambridge (2009)

3. Miller, KS, Ross, B: An Introduction to the Fractional Calculus and Fractional Differential Equations. Wiley, New York (1993)

4. Bai, C, Fang, J: The existence of a positive solution for a singular coupled system of nonlinear fractional differential equations. Appl. Math. Comput. 150, 611-621 (2004)

5. Benchohra, M, Henderson, J, Ntouyas, SK, Ouahab, A: Existence results for fractional order functional differential equations with infinite delay. J. Math. Anal. Appl. 338, 1340-1350 (2008)

6. Bai, Z: Solvability for a class of fractional m-point boundary value problem at resonance. Comput. Math. Appl. 62, 1292-1302 (2011)

7. Bai, Z, Lü, H: Positive solutions for boundary value problem of nonlinear fractional differential equation. J. Math. Anal. Appl. 311, 495-505 (2005)

8. Bai, Z, Zhang, Y: The existence of solutions for a fractional multi-point boundary value problem. Comput. Math. Appl. 60(8), 2364-2372 (2010)

9. Fečkan, M, Zhou, Y, Wang, JR: On the concept and existence of solution for impulsive fractional differential equations. Commun. Nonlinear Sci. Numer. Simul. 17, 3050-3060 (2012)

10. Fečkan, $M, Z$ Zhou, $Y$, Wang, JR: On the new concept of solutions and existence results for impulsive fractional evolution equations. Dyn. Partial Differ. Equ. 8, 345-361 (2011)

11. Jiang, W: The existence of solutions to boundary value problems of fractional differential equations at resonance. Nonlinear Anal. TMA 74, 1987-1994 (2011)

12. Wang, JR, Li, X, Wei, W: On the natural solution of an impulsive fractional differential equation of order $q \in(1,2)$. Commun. Nonlinear Sci. Numer. Simul. 17, 4384-4394 (2012)

13. Wang, JR, Zhou, Y: Impulsive problems fractional evolution equations and optimal controls in infinite dimensional spaces. Topol. Methods Nonlinear Anal. 38, 17-43 (2011)

14. Wang, JR, Zhou, Y, Fečkan, M: Nonlinear impulsive problems for fractional differential equations and Ulam stability. Comput. Math. Appl. 64, 3389-3405 (2012)

15. Wang, JR, Zhou, Y, Fečkan, M: On recent developments in the theory of boundary value problems for impulsive fractional differential equations. Comput. Math. Appl. 64, 3008-3020 (2012)

16. Zhang, S: Positive solutions for boundary value problem of nonlinear fractional differential equations. Electron. J. Differ. Equ. 2006, 36 (2006) 
17. Zhang, Y, Bai, Z: Existence of solutions for nonlinear fractional three-point boundary value problems at resonance. J. Appl. Math. Comput. 36, 417-440 (2011)

18. Lakshmikantham, V, Bainov, DD, Simeonov, PS: Theory of Impulsive Differential Equations. Worlds Scientific, Singapore (1989)

19. Samoilenko, AM, Perestyuk, NA: Impulsive Differential Equations. Worlds Scientific, Singapore (1995)

20. Liu, $B, Y u$, J: Existence of solution for $m$-point boundary value problems of second-order differential systems with impulses. Appl. Math. Comput. 125, 155-175 (2002)

21. Mawhin, J: Topological Degree and Boundary Value Problems for Nonlinear Differential Equations. CBMS-NSF Regional Conference Series in Applied Mathematics. Am. Math. Soc., Providence (1979)

doi:10.1186/s13661-014-0247-7

Cite this article as: Chen et al.: Solvability for an impulsive fractional multi-point boundary value problem at resonance. Boundary Value Problems 2014 2014:

Submit your manuscript to a SpringerOpen ${ }^{\circ}$ journal and benefit from:

- Convenient online submission

Rigorous peer review

- Immediate publication on acceptance

- Open access: articles freely available online

- High visibility within the field

- Retaining the copyright to your article 